\title{
A System for Comprehensive Comparison of Serial ECG Beats and Serial ECG Recordings
}

\author{
Chr Zywietz ${ }^{1}$, B Widiger ${ }^{2}$, R Fischer ${ }^{2}$ \\ ${ }^{1}$ BIOSIGNA, Hannover, Germany; ${ }^{2}$ Medical School, Hannover, Germany
}

\begin{abstract}
Quantitative analysis of serial ECG records is the most challenging requirement for computer electrocardiography.

A short review on ECG Variability is given. It is explained in which way the HES ECG analysis program has been extended to visualize and quantify ECG beat to beat and record variability. New features such as computation of standard error figures and confidence intervals for measurements have been embedded into the HES ECG analysis program. By means of these features data are available to support appropriate statistical testing of serial ECG recordings. Also, a statistical model is briefly described for estimation of the sources of variance in multiple serial recordings.
\end{abstract}

\section{Introduction}

A growing number of occasions and increasing accuracy requirements put new demands on serial comparison of ECGs. By serial comparison we mean in the context of this paper both: comparison of consecutive recordings, taken, e.g., before and after specific cardiologic tests (Tilt test, PTCA), during a drug study or in long term monitoring of therapy effects, and also comparison of single beats within one ECG recording.

Influential factors in serial comparison of ECG records are the usually slightly different locations of lead placement, unknown positional changes at the various recordings and often differences in heart rate. Also, different equipment performance with different filter settings may be involved.

First attempts to perform serial comparison of beats (Beat to beat variability BBV) and of vector cardiographic recordings have been reported, for instance by Fischmann [1], Pipberger [2,3], Bonner [4], Balda [5] Macfarlane [6], McManus [7], Fayn [8] and others. These tests focused mainly on changes of diagnostic statements. Today the accuracy requirements are higher and more challenging: beat comparison for beat typing ,e.g., for assessment of T-wave alternans or at signal averaging for Late Potential detection and assessment of drug induced ECG changes.

\section{Methods of serial comparison within Hannover ECG System}

\subsection{Comparison for clinical routine}

An interesting approach has been published by Pipberger [2]. Using a classification scheme based on the Bayesian likelihood ratio he did, e.g., calculate for a three (diagnostic) groups model (e.g. NOR., HYP., INF.) the allocation probabilities for each category. The three probabilities were then be graphed as one point in a triangular grid. The perpendicular distance from the point inside the equilateral triangle to a side of the equi-lateral triangle is proportional to the probability level. The sum of the three perpendicular distances to the three sides must be constant since the underlying model assumes to be exhaustive and mutual exclusive for the three categories. Location and movement of the "characteristic" diagnostic point within the triangle displayed very effectively success of a therapy or progress in the development of a disease in long term monitoring.

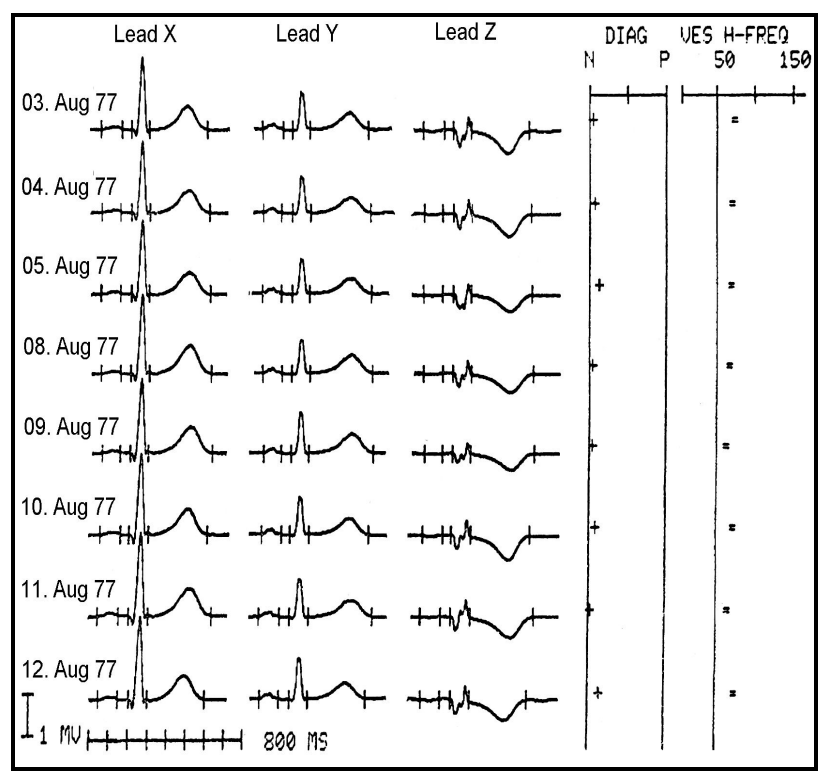

Figure 1. Example of serial VCG HES analysis reports 
All records are taken from one healthy male person. On the left hand side of fig. 1 recording date and the Representative Cycles are printed. In the next column the diagnostic allocation - most left $=$ definite Normal, most right $=$ definite Abnormal $(\mathrm{P})$ is marked $(+)$. The third column would show the number of extra systoles and the most right column depicts a marker $(=)$ for the heart rate of the analysed 10 s record.

Both of the described display modes make possible a quick and easy qualitative understanding of serial record analysis results. However, graphical plots are not sufficient if quantitative effects need to be assessed.

\subsection{Assessment of quantitative changes in serial recordings}

Table 1 shows the key measurements of VCGs from figure 1 (one healthy male). Each record did have a length of 10s. The records were taken during a study from a number of healthy males to get estimates for VCG variability within a period of approximately one month. To exclude variability from electrode displacement the electrode locations were marked and the records were taken in the morning approximately at the same time.

There are a couple of remarkable observations: (1) The vector magnitude (R-Max as well as all other amplitudes) have coefficients of variation $6.4-13.4 \%$. (2) The QRS elevation is relatively stable $\left(\mathrm{STD}=1.9^{\circ}\right)$ (3) The largest relative variability has been found in the $\mathrm{T}$-wave. The coefficient of variation reaches $13.5 \%$ and the largest $\mathrm{T}$-amplitude difference between two records exceeds $300 \mu \mathrm{V}$.
Table 1. Variability of key measurements in serial recordings.

\begin{tabular}{|c|c|c|c|c|c|c|c|c|c|}
\hline $\begin{array}{l}\text { Date of } \\
\text { Acquis. }\end{array}$ & $\begin{array}{c}\text { QRS } \\
\text { Dur. } \\
\text { ms }\end{array}$ & $\begin{array}{c}\text { R-Max } \\
\mu \mathrm{V}\end{array}$ & $\begin{array}{c}\text { QRS } \\
\text { Elev. } \\
\circ\end{array}$ & $\begin{array}{c}\text { R-X } \\
\text { Ampl. } \\
\mu \mathrm{V}\end{array}$ & $\begin{array}{c}\text { R-Y } \\
\text { Ampl. } \\
\mu \mathrm{V}\end{array}$ & $\begin{array}{c}\text { Q-Z } \\
\text { Ampl. } \\
\mu \mathrm{V}\end{array}$ & $\begin{array}{c}\text { T-Max } \\
\mu \mathrm{V}\end{array}$ & $\begin{array}{c}\text { HF } \\
\text { BPM }\end{array}$ & $\begin{array}{l}\text { QT } \\
\text { ms }\end{array}$ \\
\hline$A_{u}$ & 92 & 2047 & 26 & 1816 & 935 & -442 & 945 & 75 & 394 \\
\hline 7 & 96 & 030 & 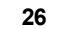 & 1819 & 963 & -419 & 920 & 70 & 410 \\
\hline 5. Auq 77 & 94 & 148 & 25 & 1916 & 913 & 374 & 834 & 70 & 412 \\
\hline 8. Auq 77 & 96 & 297 & 23 & 2108 & 910 & 366 & 1041 & 65 & 418 \\
\hline & 94 & 226 & 28 & 1958 & 1032 & -240 & 984 & 60 & 428 \\
\hline 10. & 98 & 2314 & 23 & 2118 & 991 & -377 & 1007 & 70 & 408 \\
\hline & 100 & 372 & 24 & 2171 & 1011 & -374 & 1009 & 60 & 430 \\
\hline & 96 & 35 & 26 & 2144 & 1067 & -356 & 899 & 75 & 398 \\
\hline 15. Aug 77 & 98 & 2171 & 26 & 1955 & 971 & -397 & 704 & 74 & 396 \\
\hline 16. Aug 77 & 98 & 2099 & 27 & 1869 & 1030 & -401 & 786 & 77 & 388 \\
\hline 25. Aug 77 & 90 & 1906 & 27 & 1662 & 873 & -342 & 727 & 75 & 396 \\
\hline 26. Aug 77 & 94 & 1842 & 29 & 1584 & 891 & -393 & 750 & 73 & 400 \\
\hline$\overline{\text { Mean }}$ & 95.5 & 2148.9 & 25.8 & 1926.7 & 965.6 & -373.4 & 883.8 & 70.3 & 406.5 \\
\hline Std. [ & 2.8 & 170.6 & 1.9 & 189.0 & 62.2 & 50.1 & 119.8 & 5.8 & 13.6 \\
\hline & 3. & & 7. & & & 73.4 & & 8.3 & 3.3 \\
\hline Std. Error & 0.9 & 54.0 & 0.6 & 59.8 & 19.7 & 15.9 & 37.9 & 1.8 & 4.3 \\
\hline
\end{tabular}

The variability shown here is smaller than in recordings where, e.g., the electrode location and other experimental parameters are monitored less carefully. Also the BBV needs to be considered. Each ECG measurement should consist of the mean value accompanied by it's standard error for estimation of confidence intervals. This is of outmost importance for correct statistical testing when serial recordings are to be compared in clinical studies or therapy monitoring.

To support this we have added to the HES-ECG analysis programs features that allow to evaluate the BBV and to provide the standard errors for a set of selectable parameters. This is illustrated in figures 3 and 4 (next page).



Figure 2. Example of beat to beat variability displayed as vector-loops from limb and chest leads 


\section{The HES system for serial analysis}

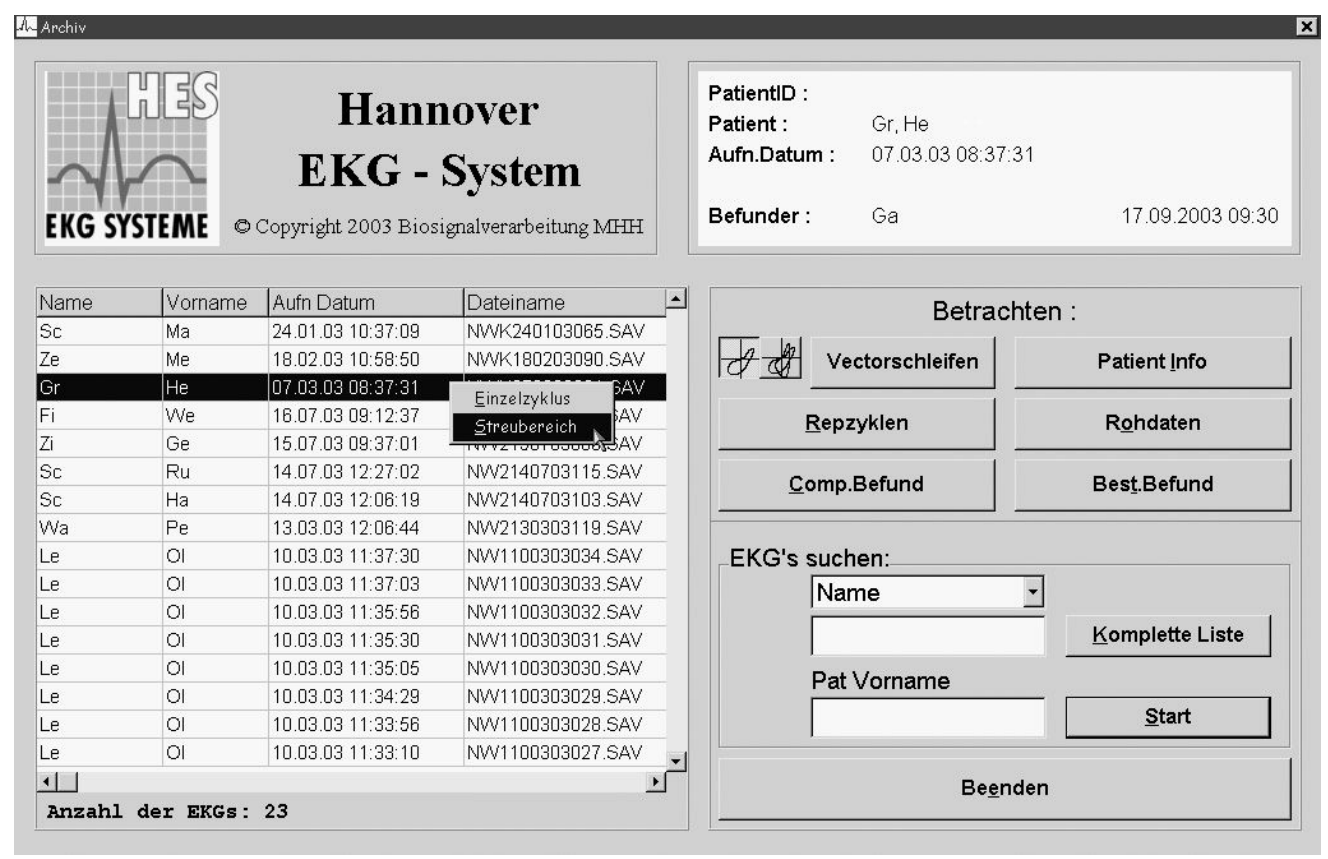

Figure 3. Analysis of BBV may be done in the overreading module of the HES analysis system. Once a record is chosen averaging is possible interactively beat by beat or the computed average beat and it's dispersion will be displayed.

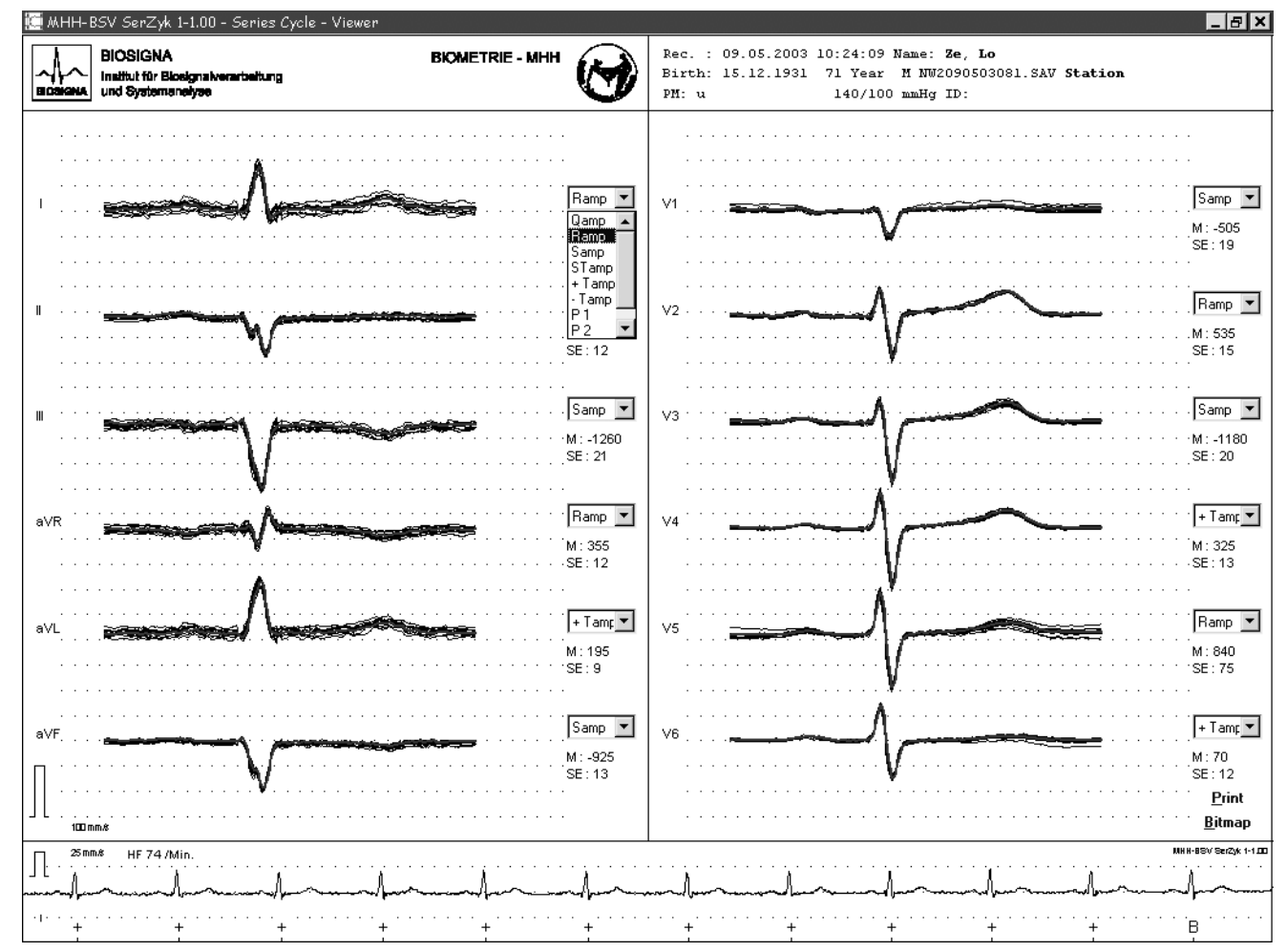

Figure 4. The superimposed ECG cycles (+ included in average) is shown. Mean and standard error of any parameter selected within the "Combo box" may be displayed and print out. Parameter selection is possible independently per lead. 


\section{Summary and conclusion}

Quantitative analysis of serial ECG records is the most challenging requirement for computer electrocardiography. Many factors introduce ECG variability. For all relevant measurements the determination of confidence intervals should be made possible. To the authors knowledge so far only Lehtinen et al. [9] have given, e.g., for ST-T measurements mean values with standard error figures which are necessary to perform meaningful statistical testing

For narrowing confidence intervals of ECG measurements a consideration of the Student $t$ distributions (see fig. 5) give some useful practical hints: at 5-7 degrees of freedom (6-8 averaged beats, respectively) the $t$ values become small and rather "stable". In other words if two measurements of ECG records are to be compared they should be based on at least 6-8 beats.

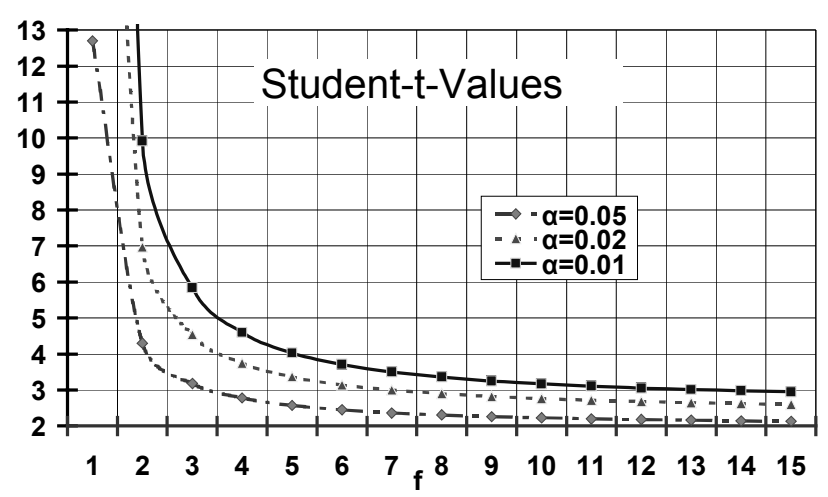

Figure 5. Student t-values for three significance levels.

Table 2. Shows commonly measured ECG amplitudes of two records during a therapeutic intervention. Comparison shows that two are significantly different.

\begin{tabular}{c|c|c|ccccc} 
Record & $\mathrm{n}$ & Value & $\begin{array}{c}\mathrm{P}_{\mathrm{I}} \\
\mu \mathrm{V}\end{array}$ & $\begin{array}{c}\mathrm{Q}_{\mathrm{I}} \\
\mu \mathrm{V}\end{array}$ & $\begin{array}{c}\mathrm{R}_{\mathrm{I}} \\
\mu \mathrm{V}\end{array}$ & $\begin{array}{c}\mathrm{S}_{\mathrm{I}} \\
\mu \mathrm{V}\end{array}$ & $\begin{array}{c}\mathrm{T}_{\mathrm{I}} \\
\mu \mathrm{V}\end{array}$ \\
\hline $2003 / 02 / 10$ & 11 & Mean & 95 & -45 & 810 & -225 & 145 \\
$"$ & $"$ & Std. Dev. & 25 & 41 & 47 & 76 & 29 \\
$"$ & $"$ & Std. Err. & 7 & 12 & 14 & 23 & 9 \\
\cline { 3 - 7 } $2003 / 05 / 09$ & 11 & Mean & 100 & -45 & 860 & -160 & 205 \\
$"$ & $"$ & Std. Dev. & 33 & 96 & 45 & 77 & 26 \\
$"$ & $"$ & Std. Err. & 10 & 29 & 14 & 23 & 8 \\
\hline & & $\Delta$ Mean & 5 & 0 & 50 & 65 & 60 \\
& & $t>p_{0.01} ?$ & - & - & + & - & + \\
\hline
\end{tabular}

The correct statistical testing becomes more complicated if series of ECG recordings are to be compared. To assess differences the appropriate approach is to perform an analysis of variance which could provide not only the necessary test parameters but also estimates for the contributions of the involved influence factors. A model equation is given by:

$$
\xi_{i j k}=\mu+a_{i}+b_{j}+c_{k}+a b_{i j}+a c_{i k}+b c_{i k}+a b c_{i j k}+\varepsilon_{i j k}
$$

where

$\xi_{\mathrm{ijkl}}$ the single measurement value

$\mu$ : total mean

$\mathrm{a}_{\mathrm{i}}, \mathrm{b}_{\mathrm{j}}: \quad$ influence of beat , person $\sim \mathrm{N}\left(0, \sigma_{\mathrm{A}}{ }^{2}\right) \mathrm{N}\left(0, \sigma_{\mathrm{B}}{ }^{2}\right)$

$\mathrm{c}_{\mathrm{k}}$ : $\quad$ influence of day $\sim \mathrm{N}\left(0, \sigma_{\mathrm{k}}{ }^{2}\right)$

$\mathrm{ab}_{\mathrm{ij}}$ : $\quad$ interaction beat and person $\quad \sim \mathrm{N}\left(0, \sigma_{\mathrm{AB}}{ }^{2}\right)$

$\mathrm{ac}_{\mathrm{ik}}$ : $\quad$ interaction beat and day $\quad \sim \mathrm{N}\left(0, \sigma_{\mathrm{AC}}{ }^{2}\right)$

$\mathrm{abc}_{\mathrm{ijk}} \quad$ interaction beat, person, day $\sim \mathrm{N}\left(0, \sigma_{\mathrm{ABC}}{ }^{2}\right)$

$\varepsilon_{\mathrm{ijk}}$ : measurement and random error $\quad \sim \mathrm{N}\left(0, \sigma^{2}\right)$

Indexes: $i=1 \quad$ number of beats measured

$\mathrm{j}=1 \quad$ number of persons

$\mathrm{k}=1 \quad$ number of measurement days

The new features embedded within the HES ECG analysis program provide now the results which support appropriate statistical testing of serial ECG recordings

\section{References}

[1] Fischmann E, Cosma J, Pipberger H. Beat to beat and observer of the electrocardiogram. Am. heart J; April 1968:465-72

[2] Pipberger HV, Dunn RA, Pipberger H. Automated Comparison of Serial Electrocardiograms. In: Editor Abel H. Adv. Cardiol., Karger, Basel 1976; vol 16:157-65

[3] Pipberger H, Sabharwawal SC, Pipberger HA. Computer Analysis of Sequential Electrocardiograms. In: Editors van Bemmel JH, Willems JL. Proceedings of the IFIP Working Conference Trends in Computer Processed Electrocardio-grams. North Holland Publish. Comp. 1977;303-8.

[4] Bonner RE. The IBM Program. In: Editors van Bemmel JH, Willems JL. Proceedings of the IFIP Working Conference Trends in Computer Processed Electrocardio-grams. North Holland Publish. Comp. 1977;133-6

[5] Balda RA, Diller G, Deardorff E, Doue J, Hsieh P. The HPECG Analysis program. In: Editors van Bemmel JH, Willems JL. Proceedings of the IFIP Working Conference Trends in Computer Processed Electrocardiograms. North Holland Publish. Comp. 1977; 197-204

[6] Macfarlane PW, Lawrie TDV. Serial ECG Processing II. In: Editors van Bemmel JH, Willems JL. Proceedings of the IFIP Working Conference Trends in Computer Processed Electrocardiograms. North Holland Publish. Comp. 1977;311-18

[7] McManus CD, Doyle JT, Pipberger HV. Year-to-Year Variation of the Orthogonal Electrocardiogram and Vectorcardiogram among 243 Normal White males. J. Electrocardiology 1984;17 (2):107-14

[8] Fayn J, Rubel P. CAVIAR, a serial ECG processing system for the Comparative Analysis of VCGs and their Interpretaion with AutoReference to the patient. J. of Electrocardiology 1988; 21(Suppl.):173-6

[9] Lehtinen R, Sievänen H, Uusitalo A, Niemäla K, Turjanmaa V, Malmivuo J. Performance Characteristics of Various Exercise ECG Classifiers in Different Clinical Populations. J. Electrocardiology 1994;27:11-22

Address for correspondence.

Christoph Zywietz

BIOSIGNA Institute

Feodor-Lynen-Str.21 (Medical Park)

D 30625 Hannover/Germany

E-mail: zywietz.christoph@biosigna.de 